\title{
CONTINUOUS VERSUS INTERRUPTED SUTURES FOR EPISIOTOMY WOUND REPAIR
}

\author{
Ashutosh Bahulekar1, Babita Vaswani², Rajkumar Patange ${ }^{3}$ \\ ${ }^{1}$ Assistant Professor, Department of Obstetrics and Gynaecology, Krishna Institute of Medical Sciences, Karad. \\ ${ }^{2}$ Resident, Department of Obstetrics and Gynaecology, Krishna Institute of Medical Sciences, Karad. \\ 3 Professor and HOD, Department of Obstetrics and Gynaecology, Krishna Institute of Medical Sciences, Karad.
}

\section{ABSTRACT}

\section{BACKGROUND}

Most of the women undergoing vaginal deliveries experience perineal trauma. Considering the high prevalence of maternal morbidity in relation to perineal trauma after delivery, the need for repair and local pain, this study was conducted to present the best method of episiotomy repair with minimum complications.

The aim of this study is to compare continuous with interrupted suturing technique for the procedure of Episiotomy.

Setting and design, a prospective comparative study was carried out in the Department of OBGY at Krishna Institute of Medical Sciences, Karad.

\section{MATERIALS AND METHODS}

Patients were randomised into two groups; Group A was repaired using the continuous technique. Group B with the same match was repaired using the intermittent technique. The material used for suturing were identical in both the groups. The participants were asked about pain and use of analgesics on $1^{\text {st }}$ and $3^{\text {rd }}$ postpartum days and on followup. The results were evaluated based on severity of pain, time required for suturing and the amount of suture material used between the two groups.

\section{RESULTS}

A total of 100 patients were included in the study - 50 in each group. Less repair time was noted in continuous technique group and suture material required was also less. The comparison of pain on long-term follow-up did not show any significant difference between the two techniques.

\section{CONCLUSION}

Repair with continuous suturing was quicker and less suture material was used in comparison with interrupted suturing. There was no difference between the severities of pain in long-term period in both the techniques.

\section{KEYWORDS}

Pain, Perineum, Suture Techniques.

HOW TO CITE THIS ARTICLE: Bahulekar A, Vaswani B, Patange R. Continuous versus interrupted sutures for episiotomy wound repair. J. Evolution Med. Dent. Sci. 2016;5(95):7016-7018, DOI: 10.14260/Jemds/2016/1586

\section{BACKGROUND}

Episiotomy is a surgical incision of the perineum made to increase the vulval outlet during childbirth. ${ }^{1}$ It is reserved for cases where perineum is likely to tear; rigid perineum, complicated childbirths, good size baby and assisted deliveries. ${ }^{2}$ Maternal morbidity caused by perineal trauma in vaginal delivery is a common problem of global occurrence. ${ }^{3}$ Majority of women undergoing vaginal deliveries will experience some form of perineal trauma requiring suturing.

Financial or Other, Competing Interest: None.

Submission 21-10-2016, Peer Review 13-11-2016,

Acceptance 21-11-2016, Published 28-11-2016.

Corresponding Author:

Dr. Babita Vaswani.

Room No. 309,

IHR Hostel,

Krishna Institute of Medical Sciences,

Malkapur,

Karad 415110

Dist-Satara,

Maharashtra.

E-mail:vaswani.babita@gmail.com

DOI: $10.14260 /$ jemds $/ 2016 / 1586$

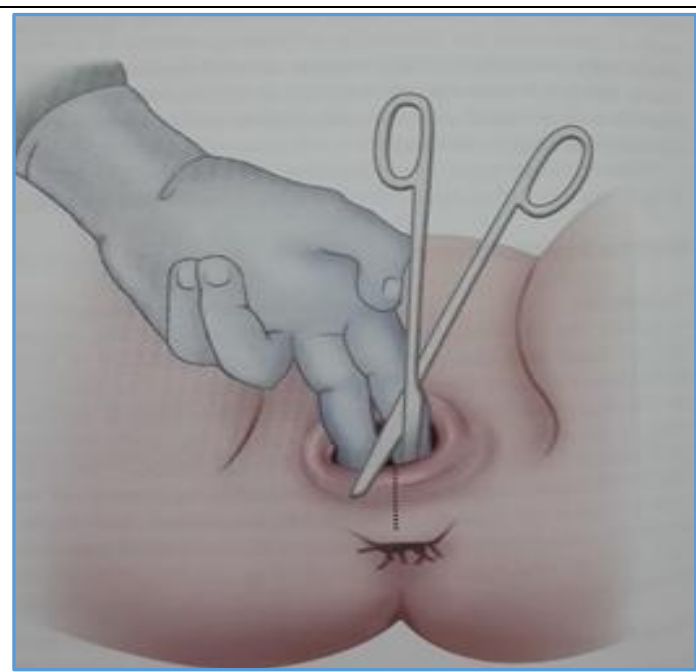

Figure 1

Episiotomies are known to provide the following Benefits ${ }^{1}$

- Speed up the birth.

- Prevent vaginal tear.

- Protect against incontinence.

- Heals easier than tears.

Haemostasis and restoration of anatomical structure of the incision site are fundamental aspects of success in all 
methods. ${ }^{1}$ The factors associated with morbidity and related to perineal trauma repair consist in the choice of the suture material used, the repair technique and the surgeon's competence. ${ }^{3,4}$ Traditionally, the vagina is stitched using a continuous locking suture and the perineal muscles and skin are repaired using intermittent sutures. ${ }^{2}$ Researchers have been suggesting for more than 70 years that the 'continuous suturing method' is better than 'traditional interrupted method. ${ }^{2}$ Despite its high prevalence and potential for morbidities such as oedema, haematoma, pain, infection and dehiscence, very limited studies have been performed in this field and there is a lack of research in its surgical repair. ${ }^{1}$ It is for this reason that we compared the two episiotomy repair methods in order to present the best method of episiotomy repair with minimum complications.
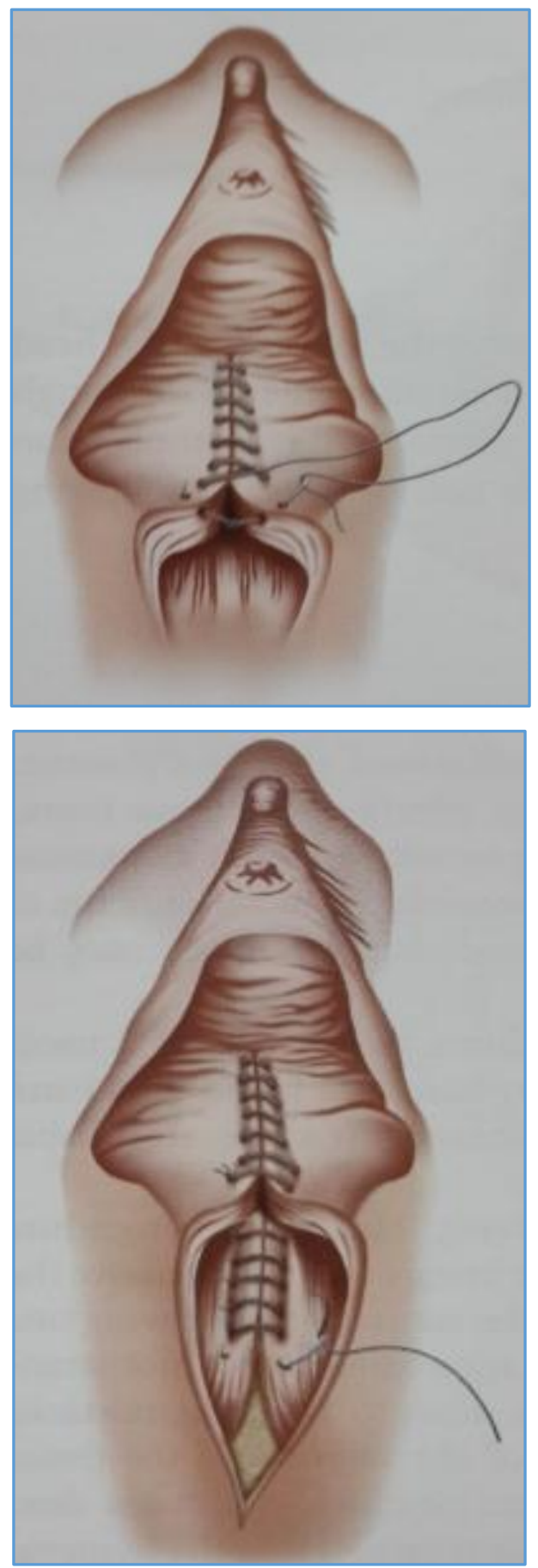

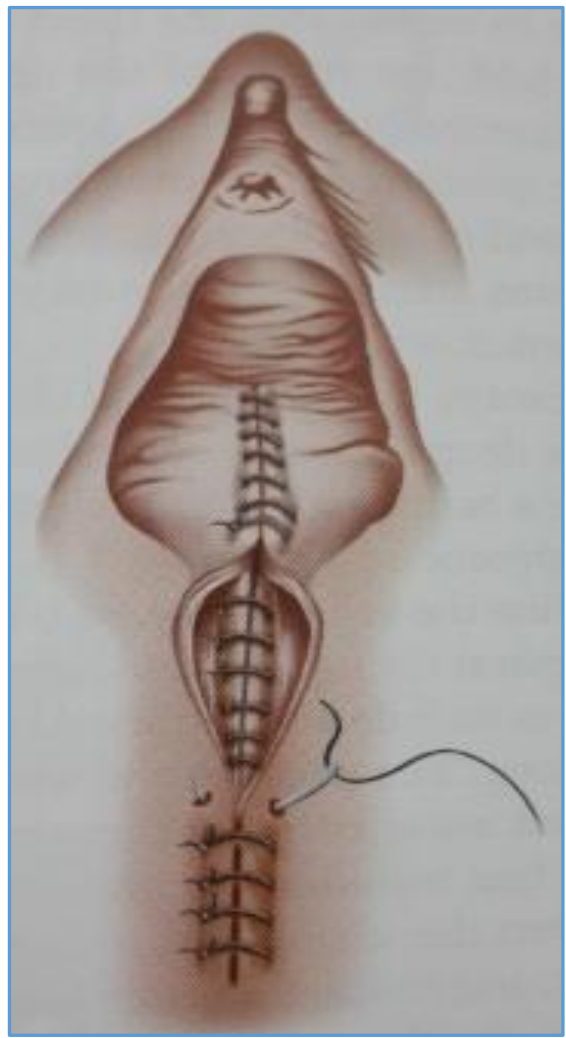

Figure 2

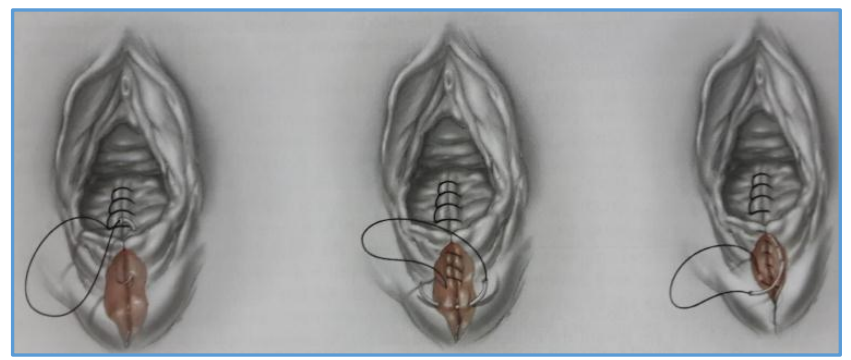

Figure 3

\section{MATERIALS AND METHODS}

A prospective comparative study was conducted in the Department of OBGY in KIMS, Karad over a period of 1 month. A total of 100 patients were included in the study. Patients were randomly divided into 2 groups:

- Group A: Continuous suturing: Continuous suture technique with continuous locking sutures in the vagina, perineum muscles and subcutaneous sutures for skin.

- Group B: Intermittent suturing: Continuous locking sutures in the vagina, interrupted sutures in the perineal muscles and mattress sutures for skin.

\section{Inclusion Criteria ${ }^{2}$}

- Term gestation.

- Viable new-born without serious congenital malformations.

- $\quad$ Parity $\leq 2$.

- Assisted breech vaginal delivery.

\section{Exclusion Criteria ${ }^{2}$}

- Instrumental deliveries. 
- Patients suffering from diabetes mellitus, chronic illness like liver, heart, renal diseases, etc.

- Haemoglobin $<8 \mathrm{~g} / \mathrm{dL}$.

- Parity $\geq 3$.

- Preterm delivery.

Immediately after repair of the perineum, the number of suture packets used were counted and the patients were asked about pain on 1st and 3rd day after delivery. Verbal Rating Score (VRS 0 - 3 ) consists of a scale from 0 to $3(0=$ no pain, 1 = mild, 2 = moderate, 3 = severe pain) was used to evaluate pain severity at 1 st and 3rd day after episiotomy repair after delivery. ${ }^{1}$ Also the time required for suturing was noted and compared.

\section{RESULTS AND DISCUSSION}

\begin{tabular}{|c|c|c|}
\hline $\begin{array}{c}\text { Technique of } \\
\text { Suturing }\end{array}$ & $\begin{array}{c}1 \text { Packet }(\mathrm{n}= \\
\%)\end{array}$ & $\begin{array}{c}>1 \text { Packet }(\mathrm{n}= \\
\%)\end{array}$ \\
\hline Continuous & $80 \%$ & $20 \%$ \\
\hline Intermittent & $16 \%$ & $84 \%$ \\
\hline \multicolumn{3}{|c|}{ Table 1. Suture Packets Used According to Technique } \\
Employed
\end{tabular}

As shown in Table/Fig. 4, among 50 patients who underwent continuous episiotomy suturing, maximum patients i.e. $80 \%$ required only one packet of chromic catgut, whereas in other group of intermittent suturing $84 \%$ patients required more than one packet.

\begin{tabular}{|c|c|c|c|c|}
\hline & $\begin{array}{c}\text { VRS 0 } \\
\text { (n= \%) }\end{array}$ & $\begin{array}{c}\text { VRS 1 } \\
\text { (n= \%) }\end{array}$ & $\begin{array}{c}\text { VRS 2 } \\
\text { (n= \%) }\end{array}$ & $\begin{array}{c}\text { VRS 3 } \\
\text { (n= \%) }\end{array}$ \\
\hline $\begin{array}{c}\text { 1st day } \\
\text { Continuous } \\
\text { Intermittent }\end{array}$ & $6 \%$ & $68 \%$ & $18 \%$ & $8 \%$ \\
\hline $\begin{array}{c}\text { 3rd day } \\
\text { Continuous } \\
\text { Intermittent }\end{array}$ & $64 \%$ & $20 \%$ & $52 \%$ & $24 \%$ \\
\hline \multicolumn{6}{|c|}{$\begin{array}{c}20 \% \\
\text { Table 2. Relationship of Suturing Technique and } \\
\text { Severity of Pain at 1st and 3rd Day of Delivery }\end{array}$} \\
\hline
\end{tabular}

As per Table/Fig. 5, only $26 \%$ patients complained of pain of Grade 2 and more on 1st day of delivery and it was reduced to only $16 \%$ on $3^{\text {rd }}$ day, rest of the patients were comfortable in terms of pain on first day of delivery in continuous suturing technique, whereas $76 \%$ of the patients complained of pain of severity Grade 2 and more on 1st day and $50 \%$ on 3rd day in intermittent suturing technique, which suggests remarkable difference in pain severity in these two different suturing techniques.

\begin{tabular}{|c|c|c|}
\hline Technique of Suturing & $<\mathbf{1 0}$ Minutes & > 10 Minutes \\
\hline Continuous & $88 \%$ & $12 \%$ \\
\hline Intermittent & $18 \%$ & $82 \%$ \\
\hline \multicolumn{3}{|c|}{ Table 3. Time Required According to Technique } \\
Employed
\end{tabular}

As per the Table/Fig. 6, 88\% of patients in continuous suturing technique required less than 10 minutes for suturing, whereas $82 \%$ in intermittent suturing technique required more than 10 minutes.

In this comparative study in the two groups of women, the ability of the health professionals and the type of materials used were the same. ${ }^{4}$ The only difference was the suture technique. Less repair time, less suture material used and less short-term post-partum pain were the significant differences between the two groups. ${ }^{4}$ Kettle et al carried out a trial comparing the two techniques of episiotomy repair (continuous and discontinuous) using two suture materials (quick absorption and standard) and found that less pain was experienced with the continuous suture technique. ${ }^{5}$ Almeida SF, Rieco MI compared the continuous and interrupted techniques and found more pain in interrupted suture technique. ${ }^{3}$

\section{CONCLUSION}

Continuous suturing technique for perineal closure is associated with less short-term pain. The continuous technique is easily performed. In addition, it has an economical advantage that the continuous technique requires one packet of suture material per perineal repair compared to two or more packets for the interrupted method. Therefore, the continuous suturing technique is recommended for repair. The continuous technique need less time and energy and shortens the duration of mother's stay on the delivery bed and finally reduces cost.

\section{REFERENCES}

1. Tandon A, Deshpande A. Observational study of continuous versus interrupted suturing of episiotomy in rural population of India in terms of requirement of suture material and pain. Indian Journal of Basic and Applied Medical Research 2015;4(4):524-8.

2. Dash S , Nanda SS , Behera A, Mishra B. Continuous versus interrupted sutures for episiotomy wound and perineal tear repair. Scholars Journal of Applied Medical Sciences 2013;I(6):710-3.

3. Almeida SF, Riesco ML. Randomized controlled clinical trial on two perineal trauma suture techniques in normal delivery. Rev Lat Am Enfermagem 2008;16(2):272-9.

4. Mahmood S, Anwar S. Continuous versus interrupted sutures for episiotomy wound repair. Journal of Surgery Pakistan(International) 2013;18(1).

5. Kettle C, Dowswell T, Ismail KM. Absorbable suture materials for primary repair of episiotomy and second degree tears. Cochrane Database Syst Rev 2010;6:CD000006. 